\title{
Prevalence of left main Coronary Artery Disease with Diabetes and Hypertension in STEMI patients
}

\author{
FARYAD ALI ${ }^{1}$, QAZI ABDUL SABOOR ${ }^{2}$, TALHA MAHMUD ${ }^{3}$, FAHAD ALI ${ }^{4}$, HUSNAIN BASHIR ${ }^{5}$, AQEEL AHMED ${ }^{6}$, \\ WASEEM REHMAN ${ }^{7}$, ABUBAKAR HILAL $^{8}$, ARZ MUHAMMAD $^{9}$ \\ ${ }^{1}$ Registrar, Social Security Hospital, Multan Road, Lahore. \\ ${ }^{2}$ Professor \& Head Department of Cardiology, Shaikh Zayed Medical Complex, Lahore. \\ ${ }^{3}$ Professor \& Head Department of Pulmonology, Shaikh Zayed Medical Complex, Lahore. \\ ${ }^{4}$ MBBS, FCPS Cardiology, Cardiologist Wapda Hospital, Lahore. \\ ${ }^{5}$ Registrar, Department of Cardiology, Shaikh Zayed Medical Complex, Lahore. \\ ${ }^{6}$ Associate Professor, Cardiac Surgery Department, Shaikh Zayed Medical Complex, Lahore \\ ${ }^{7}$ Registrar, Department of Cardiac Surgery, Shaikh Zayed Medical Complex, Lahore \\ ${ }^{8,9}$ Senior Registrar, Shaikh Zayed Medical Complex, Lahore. \\ Correspondence to: Faryad Ali, Email: drfaryadali55@gmail.com
}

\begin{abstract}
Aim: To determine the association of left main stem disease with diabetes and hypertension in STEMI patients underwent coronary angiography

Methodology: This study was conducted at Department of Cardiology, Sheikh Zayed Hospital, Lahore during January to June 2019 where 220 patients with age ranging from 40-70 years whether male or female, presenting with STEMI, In Exposed Group: Patients presenting with STEMI having diabetes and hypertension and Unexposed Group: Patients of STEMI without diabetes and hypertension. We excluded all cases with recurrent $\mathrm{Ml}$ or undergoing recurrent $\mathrm{PCl}$ (on medical record), valvular heart disease, and cardiogenic shock. Then two groups were formed i.e. exposed group with diabetes and hypertension and unexposed group without diabetes and hypertension. All patients underwent angiography by a senior consultant cardiologist with assistance of researcher. On angiography, presence of LMS disease was $\geq 50 \%$ occlusion (stenosis) in LMS artery. Angiography reports were assessed and LMS disease was noted labeled. Patients with LMS disease was managed as per hospital protocol.

Results: In this study risk of LMS was higher among exposed group as compared to un exposed group. i.e. exposed: $19.1 \%$ \& Unexposed: $5.5 \%, \mathrm{RR}=3.50$ The risk of LMS among exposed group was higher for patients in the age group 51-60 years $(R R=8.00)$, for male patients $(R R=5.76)$ risk for $L M S$ was higher as compared to female patients in exposed group, patients with normal BMI (RR:2.20) and patients with shorter duration of STEMI in exposed group had higher risk for LMS (1-4 weeks: RR=7.54).

Conclusion: Results of this study showed that hypertensive and diabetic patients presenting with STEMI had higher risk for LMS disease.

Keywords: Left main stem, Diabetes, Hypertension, Coronary, Angiography
\end{abstract}

\section{INTRODUCTION}

ST-elevation myocardial infarction with left main coronary artery disease (CAD) is one of the most life-threatening conditions in daily clinical practice. ${ }^{1}$ The patients with severe left main stem (LMS) stenosis have a very high risk of mortality and morbidity as it supplies almost $84 \%$ of left ventricle in left dominant system.. Mortality rate of significant LMS disease is $50 \%$ at 3 year if treated medically. ${ }^{2}$ ST-Elevation Myocardial Infarction (STEMI) has special consideration due to significant contributor to morbidity and mortality. ${ }^{3}$ Among STEMI patients Diabetes mellitus is one of serious ${ }^{4}$ and hypertension is one of the most common ${ }^{5}$ risk factors for CAD. Hypertension does not have significant impact on mortality in patients with STEMI going for coronary angiography. ${ }^{6,7}$ But the consequences of hypertension and diabetes in patients with ACS going for percutaneous coronary intervention $(\mathrm{PCl})$ were studied well. However, the long term consequences of both hypertension and diabetes in patients undergoing $\mathrm{PCl}$ is not clear.

Received on 18-02-2021

Accepted on 21-05-2021
The frequency of diabetes mellitus and hypertension is increasing due to aging, urbanization, obesity, and sedentary lifestyle. he mortality and morbidity due to CAD is increased in DM patients. DM patients have more advanced CAD disease than non-diabetics. ${ }^{9}$ Hypertension is one of the most common ${ }^{4}$ risk factors for CAD .It has been noticed from literature that LMS was significantly high in patients with risk factors like diabetes and hypertension. But, discrepancy in Prevalence of left main stem disease in patient presenting with STEMI with diabetes and hypertension also noted. One study showed that frequency of LMS was $13.2 \%$ in patients with diabetes and hypertension and $3.8 \%$ in patients without diabetes and hypertension $(p=0.008)^{10}$. Another study also showed that frequency of LMS was $3.0 \%$ in patients with diabetes and hypertension and $1.1 \%$ in patients without diabetes and hypertension $(p=0.002)^{11}$. There is lack of local data which could help us to predict LMS disease in diabetics and hypertensive patients and make treatment plan accordingly.

Rationale of this study is to determine the association of LMS disease with diabetes and hypertension in patients underwent coronary angiography. This study was done to attain local evidence which in future would help us in 
implementing the screening and plan management strategies in STEMI patient for LMS disease, to prevent the hazardous consequences.

\section{METHODOLOGY}

This study was conducted at Department of Cardiology, Sheikh Zayed Hospital, Lahore during January to June 2019 where 220 patients with age ranging from 40-70 years whether male or female, presenting with STEMI, In Exposed Group: Patients presenting with STEMI having diabetes and hypertension and Unexposed Group: Patients of STEMI without diabetes and hypertension. We excluded all cases with recurrent $\mathrm{Ml}$ or undergoing recurrent $\mathrm{PCI}$ (on medical record), valvular heart disease, and cardiogenic shock. Then two groups were formed i.e. exposed group with diabetes and hypertension and unexposed group without diabetes and hypertension. All patients underwent angiography by a senior consultant cardiologist with assistance of researcher. On angiography, presence of LMS disease was $\geq 50 \%$ occlusion (stenosis) in LMS artery. Angiography reports were assessed and LMS disease was noted labeled. Patients with LMS disease was managed as per hospital protocol. Data was taken and analyzed in SPSS version 21. Mean \pm SD for BMI, age, duration of STEMI was analyzed. Frequency and percentage was analyzed for LMS and gender. To measure relation between LMS and diabetes plus hypertension relative risk was analyzed. $R R>1$ was taken as significant.

\section{RESULTS}

Means age of patients in exposed and unexposed group was $57.76 \pm 8.71$ and $56.27 \pm 9.44$ years. In exposed group $63(57.3 \%)$ patients were male and $47(42.7 \%)$ patients were female. In unexposed group 66(60\%) patients were male and $44(40 \%)$ were female. Mean BMl of patients in exposed and in unexposed group was 29.68 \pm 5.66 and 32.86 \pm 4.41 . Mean duration of STEMI in exposed and unexposed group was $6.67 \pm 3.66$ and $6.89 \pm 3.55$. Mean stenosis in exposed and in unexposed group was $42.50 \pm 18.57$ and $36.35 \pm 11.55$.LMS disease in exposed and in unexposed group was seen diagnosed in $19.1 \%$ and $5.5 \%$ patients. Risk of LMS among exposed was 3.50 times higher as that of unexposed group. Table-1

Table-1: LMS in Study groups

\begin{tabular}{|l|l|l|l|}
\hline & Exposed & Unexposed & Total \\
\hline Yes & $21(19.1 \%)$ & $6(5.5 \%)$ & 27 \\
\hline No & $89(80.9 \%)$ & $104(94.5 \%)$ & 193 \\
\hline Total & 110 & 110 & 220 \\
\hline
\end{tabular}

Relative Risk: 3.50 (1.46-8.33) p-value $=0.004$

Table-2: LMS in Study groups stratified for age of patients

\begin{tabular}{|c|c|c|c|c|c|}
\hline Age & LMS & Exposed & Unexposed & RR & $\mathrm{Cl}$ \\
\hline \multirow[b]{2}{*}{$40-50$} & Yes & $5(18.5 \%)$ & $2(5.9 \%)$ & \multirow[b]{2}{*}{3.14} & \multirow{2}{*}{$\begin{array}{l}0.66- \\
14.98\end{array}$} \\
\hline & No & $22(81.5 \%)$ & $32(94.1 \%)$ & & \\
\hline \multirow{2}{*}{$51-60$} & Yes & $8(22.9 \%)$ & $1(2.9 \%)$ & \multirow{2}{*}{8.00} & \multirow{2}{*}{$\begin{array}{l}1.05- \\
60.63\end{array}$} \\
\hline & No & $27(77.1 \%)$ & $34(97.1 \%)$ & & \\
\hline \multirow{2}{*}{$61-70$} & Yes & $8(16.7 \%)$ & $3(7.3 \%)$ & \multirow{2}{*}{2.27} & \multirow{2}{*}{$\begin{array}{l}0.64- \\
8.02\end{array}$} \\
\hline & No & $40(83.3 \%)$ & $38(92.7 \%)$ & & \\
\hline
\end{tabular}

Highest risk was seen in patients in the age group 51-60 years in exposed group. i.e. $R R=8.00 T a b l e-2$. Frequency of LMS disease in women were higher group as compare to males $21.3 \%$ vs $17.5 \%$ but RR was higher in ,ales as comare to females 5.76 vs 2.34 Table-3 BMI and duration of STEMI was presented in. Table-4-5

Table-3: LMS in Study groups stratified for Gender of patients

\begin{tabular}{|c|c|c|c|c|c|}
\hline Gender & LMS & Exposed & Unexposed & RR & $\mathrm{Cl}$ \\
\hline \multirow[b]{2}{*}{ Male } & Yes & $11(17.5 \%)$ & $2(3 \%)$ & \multirow[b]{2}{*}{5.76} & \multirow{2}{*}{$\begin{array}{l}1.32- \\
24.97\end{array}$} \\
\hline & No & $52(82.5 \%)$ & $64(97 \%)$ & & \\
\hline \multirow{2}{*}{ Female } & Yes & $10(21.3 \%)$ & $4(9.1 \%)$ & \multirow{2}{*}{2.34} & \multirow{2}{*}{$\begin{array}{l}0.79- \\
6.92\end{array}$} \\
\hline & No & $37(78.7 \%)$ & $40(90.9 \%)$ & & \\
\hline
\end{tabular}

Table-4: LMS in Study groups stratified for BMI of patients

\begin{tabular}{|c|c|c|c|c|c|}
\hline BMI & LMS & Exposed & Unexposed & $\mathbf{R R}$ & $\mathbf{C l}$ \\
\hline \multirow{2}{*}{ Normal } & Yes & $12(36.4 \%)$ & $0(0 \%)$ & \multirow[b]{2}{*}{0} & \multirow{2}{*}{$\begin{array}{l}0.16- \\
28.77\end{array}$} \\
\hline & No & $21(63.6 \%)$ & $2(100 \%)$ & & \\
\hline \multirow{2}{*}{ Overweight } & Yes & $9(36 \%)$ & $6(19.4 \%)$ & \multirow{2}{*}{1.86} & \multirow{2}{*}{$\begin{array}{l}0.76- \\
4.52\end{array}$} \\
\hline & No & $16(64 \%)$ & $25(80.6 \%)$ & & \\
\hline \multirow{2}{*}{ Obese } & Yes & $0(0 \%)$ & $0(0 \%)$ & & \\
\hline & No & $52(100 \%)$ & $77(100 \%)$ & & \\
\hline
\end{tabular}

Table-5: LMS in Study groups stratified for duration of STEMI

\begin{tabular}{|c|c|c|c|c|c|}
\hline $\begin{array}{l}\text { STEMI } \\
\text { (Duration) }\end{array}$ & LMS & Exposed & Unexposed & RR & $\mathrm{Cl}$ \\
\hline \multirow{2}{*}{ 1-4 Weeks } & Yes & $4(11.1 \%)$ & $0(0 \%)$ & \multirow{2}{*}{7.54} & \multirow{2}{*}{$\begin{array}{l}0.42- \\
134.67\end{array}$} \\
\hline & No & $32(88.9 \%)$ & $30(100 \%)$ & & \\
\hline \multirow{2}{*}{ 5-8 Weeks } & Yes & $8(25 \%)$ & $3(8.3 \%)$ & \multirow{2}{*}{3.00} & \multirow{2}{*}{$\begin{array}{l}0.86- \\
10.35\end{array}$} \\
\hline & No & $24(75 \%)$ & $33(91.7 \%)$ & & \\
\hline \multirow{2}{*}{ 9-12 Weeks } & Yes & $9(21.4 \%)$ & $3(6.8 \%)$ & \multirow{2}{*}{3.14} & \multirow{2}{*}{$\begin{array}{l}0.91- \\
10.82\end{array}$} \\
\hline & No & $33(78.6 \%)$ & $41(93.2 \%)$ & & \\
\hline
\end{tabular}

\section{DISCUSSION}

ST-elevation myocardial infarction with left main coronary artery disease (CAD) is one of the most life-threatening conditions in daily clinical practice However, in patient presenting with unstable angina and undergoing $\mathrm{PCl}$, hypertension was the only independent risk factor that predicted mortality. ${ }^{12}$ Long term mortality was strongly predicted by insulin dependent diabetes mellitus as compared with non-diabetic mellitus or non- Insulin treated diabetes mellitus patients. ${ }^{13}$ After receiving coronary angiography, the short and mid-term consequences were worst in diabetic patients with ACS compared to nondiabetic patients with ACS. ${ }^{14-17}$

For patients presenting with ACS and having both hypertension and diabetes mellitus, the presence of both DM and hypertension increases the likelihood of mortality than in patients with hypertension or diabetes mellitus alone. ${ }^{17}$ mid-term outcomes in stable CAD patients receiving $\mathrm{PCl}$ were still worse in diabetic patients. ${ }^{18}$ However, the long term consequences of both hypertension and diabetes in patients undergoing $\mathrm{PCl}$ are still not clear.

LMS disease is an important and independent risk factor which causes an increased mortality and morbidity in patients undergoing diagnosis and treatment with CAD. LMS pathology is often silent, with unpredictable presentation: as such it poses diagnostic and management challenges. With the advent of drug-eluting stents, improvements in percutaneous intervention and aggressive interventional centers, the management of left main coronary disease is no longer purely surgical ${ }^{19}$. 
In this study, risk of LMS was higher among exposed group as compared to unexposed group. i.e. exposed $19.1 \%$ \& Unexposed: $5.5 \%, R R=3.50$ The risk of LMS among exposed group was higher for patients in the age group 51-60 years $(R R=8.00)$, for male patients $(R R=5.76)$ risk for LMS was higher as compared to female patients in exposed group, patients with normal BMI (RR:2.20) and patients with shorter duration of STEMI in exposed group had higher risk for LMS (1-4 weeks: $R R=7.54)$.

One study showed that frequency of LMS was $13.2 \%$ in patients with diabetes and hypertension and $3.8 \%$ in patients without diabetes and hypertension $(p=0.008) .{ }^{10}$ Another study also showed that frequency of LMS was $3.0 \%$ in patients with diabetes and hypertension and $1.1 \%$ in patients without diabetes and hypertension $(p=0.002) .{ }^{11}$

Tanjima Parvin in his study reported higher fluency of LMS among diabetics compared to non-diabetics. i.e. $21 \%$ $\& 5 \%$, p-value $=0.031^{20}$ All the above-mentioned studies did not calculated relative risk for LMS in patients with and without diabetes and hypertension.

It has been noticed from literature that LMS was significantly high in patients with risk factors like diabetes and hypertension. But, not much work has been done in this regard and also there is lack of local data which could help us to predict LMS disease in diabetics and hypertensive patients and make treatment plan. Consider Hybrid cath lab and cardiac surgery back up in such patients. This data of high risk cardiac disease may be used in health education and risk awareness campaigns among general population specifically in diabetic and hypertensive patients.

\section{CONCLUSION}

Results of this study showed that hypertensive and diabetic patients presenting with STEMI undergoing coronary angiography had higher risk for LMS disease.

\section{REFERENCES}

1. Khripun A, Malevannyi M, Kulikovskikh Y. Long-term outcomes of unprotected left main stem PCI in STEMI. European Heart Journal 2013;34(suppl 1

2. Predescu LM, Zarma L, Platon P, Postu M, Bucsa A, Croitoru M, et al. Current treatment of left main coronary artery disease. Cor et Vasa 2016 2016/06/01/;58(3):e328-e39.

3. Choudhury T, West NE, El-Omar M. ST elevation myocardial infarction. Clin Med. 2016;16(3):277-82

4. Luca GD, Parodi G, Sciagrà R, Bellandi B, Vergara R, Migliorini A. Effect of diabetes on scintigraphic infarct size in STEMI patients undergoing primary angioplasty. Diabetes/Metabolism Research and Reviews. 2015;31:322-8

5. Scholz KH, Maier SKG, Maier LS, Lengenfelder B, Jacobshagen C, Jung $\mathrm{J}$, et al. Impact of treatment delay on mortality in ST-segment elevation myocardial infarction (STEMI) patients presenting with and without haemodynamic instability: results from the German prospective, multicentre FITT-STEMI trial. Eur Heart J. 2018;39(13):1065-74

6. Lazzeri C, Valente S, Chiostri M, Attana P, Picariello C, Gensini GF. Impact of hypertension on short-and long-term prognoses in patients with ST elevation myocardial infarction and without previously known diabetes. Heart and vessels 2012;27(4):370-6.

7. Cecchi E, D'Alfonso MG, Chiostri M, Parigi E, Landi D, Valente S, et al. Impact of hypertension history on short and long-term prognosis in patients with acute myocardial infarction treated with percutaneous angioplasty: comparison between STEMI and NSTEMI. High Blood Pressure \& Cardiovascular Prevention 2014;21(1):37-43.

8. Lin M-J, Chen C-Y, Lin H-D, Wu H-P. Impact of diabetes and hypertension on cardiovascular outcomes in patients with coronary artery disease receiving percutaneous coronary intervention. BMC cardiovascular disorders 2017;17(1):12.

9. Krul MM, Bogaard K, Knol RJ, van Rossum AC, Knaapen P, Cornel $\mathrm{JH}$, et al. Coronary artery disease in patients with atypical chest pain with and without diabetes mellitus assessed with coronary CT angiography. BMJ Open Diabetes Research and Care 2014;2(1):e000004

10. Hussein MF. Clinical and Angiographic Findings in Diabetic Versus Non-Diabetic Iraqi Patients with Ischemic Heart Disease (A Single Center Experience). Iraqi Academic Scientific Journal 2011;10(3):339-46.

11. Lee MG, Jeong MH, Ahn Y, Chae SC, Hur SH, Hong TJ, et al. Comparison of clinical outcomes following acute myocardial infarctions in hypertensive patients with or without diabetes. Korean circulation journal 2009;39(6):243-50.

12. López-Mínguez JR, Fuentes ME, Doblado M, Merchán A, Martínez A, González R, et al. Prognostic role of systemic hypertension and diabetes mellitus in patients with unstable angina undergoing coronary stenting. Revista Española de Cardiología (English Edition) 2003;56(10):987-94.

13. Hoebers LP, Claessen BE, Woudstra P, DeVries JH, Wykrzykowska $\mathrm{JJ}$, Vis MM, et al. Long-term mortality after primary percutaneous coronary intervention for ST-segment elevation myocardial infarction in patients with insulin-treated versus non-insulin-treated diabetes mellitus. Eurolntervention: journal of EuroPCR in collaboration with the Working Group on Interventional Cardiology of the European Society of Cardiology 2014;10(1):90-6.

14. Klempfner R, Elis A, Matezky S, Keren G, Roth A, Finkelstein A, et al. Temporal trends in management and outcome of diabetic and nondiabetic patients with acute coronary syndrome (ACS): residual risk of long-term mortality persists: insights from the ACS Israeli Survey (ACSIS) 2000-2010. International journal of cardiology 2015;179:546-51.

15. Park K-H, Ahn $\mathrm{Y}$, Jeong $\mathrm{MH}$, Chae SC, Hur SH, Kim $\mathrm{YJ}$, et al. Different impact of diabetes mellitus on in-hospital and 1-year mortality in patients with acute myocardial infarction who underwent successful percutaneous coronary intervention: results from the Korean Acute Myocardial Infarction Registry. The Korean journal of internal medicine 2012;27(2):180.

16. Jensen LO, Maeng M, Thayssen P, Tilsted HH, Terkelsen CJ, Kaltoft $A$, et al. Influence of diabetes mellitus on clinical outcomes following primary percutaneous coronary intervention in patients with STsegment elevation myocardial infarction. The American journal of cardiology 2012;109(5):629-35

17. Lee $M G$, Jeong $M H$, Lee $\mathrm{KH}$, Park $\mathrm{KH}$, Sim DS, Yoon $\mathrm{HJ}$, et al Prognostic impact of diabetes mellitus and hypertension for mid-term outcome of patients with acute myocardial infarction who underwent percutaneous coronary intervention. Journal of cardiology 2012;60(4):257-63.

18. Laskey WK, Selzer F, Vlachos HA, Johnston J, Jacobs A, King III SB, et al. Comparison of in-hospital and one-year outcomes in patients with and without diabetes mellitus undergoing percutaneous catheter intervention (from the National Heart, Lung, and Blood Institute Dynamic Registry). The American journal of cardiology 2002;90(10):1062-7.

19. Chikwe J, Kim M, Goldstone AB, Fallahi A, Athanasiou T. Current diagnosis and management of left main coronary disease. European journal of cardio-thoracic surgery 2010;38(4):420-30.

20. Parvin T, Haque KS, Siddique MA, Habib SA, Rahman M, Rahman $\mathrm{MH}$, et al. Angiographic Severity of Coronary Artery Disease in Diabetic and Non-Diabetic Patients in a Tertiary Care Centre. University Heart Journal 2014;10(1):13-7. 